\title{
Joining the High-Strength Steel Sheets Used in Car Body Production
}

\author{
Luboš Kaščák", Denis Cmorej', Emil Spišák', Ján Slota \\ 1 Technical University of Košice, Faculty of Mechanical Engineering, Department of Technology, Materials and \\ Computer Support of Production, Letná 9, 04200 Košice, Slovakia \\ * Corresponding author's email: lubos.kascak@tuke.sk
}

\begin{abstract}
Nowadays, there are several important reasons for using high-strength sheets in the manufacturing of car bodies. Car manufacturers choose the steel with good formability, fatigue resistance and ability to absorb impact energy. Microalloyed steels and dual-phase steels are the materials which fulfil the above-mentioned criteria. The application of high-strength sheets has led to the development of new materials joining techniques. Mechanical joining, such as clinching, is the innovative technique to join these progressive materials. Materials of different thicknesses can be joined by clinching. The paper focuses on the comparison of the properties of the joints made by clinching and resistance spot welding. The application of resistance spot welding is still the most used joining method in car body production. These properties were investigated by tensile test and metallographic observation. The HCT600X+ZF, HCT600X+Z and HX420LAD $+Z$ steel sheets were used for the experiments. The results of tensile test show that the values of load-bearing capacity of clinched joints reached from $3900 \mathrm{~N}$ to $5900 \mathrm{~N}$ and the resistance spot welded joints reached the values of load-bearing capacity from $12000 \mathrm{~N}$ to $19500 \mathrm{~N}$. In comparison to the resistance spot welded joints, the clinched joints reached from 32 to $48 \%$ of load-bearing capacity.
\end{abstract}

Keywords: clinching, resistant spot welding, tensile test, metallography, HCT600X+ZF, HCT600X+Z, HX420LAD + Z

\section{INTRODUCTION}

One of the most important issues in the automotive industry is the safe design, light weight and enhanced of crash response of specific auto-body structures. These objectives lead to the increasing adoption of high-strength steel sheets for specific parts of auto-body members [1-3].

One of the best known high-strength steels are the high-strength low-alloy (HSLA) steel and the dual-phase (DP) steel. The DP steels have excellent formability, impact energy absorption properties and fatigue resistance in comparison with the conventional high-strength low alloy steels of similar mechanical properties. The dual-phase steels offer a combination of high strength and good formability because of their microstructure in which the hard martensitic or bainitic phase is dispersed in a ductile ferritic matrix. This type of steel is characterized by a good ability to redistribute stress and improve mechanical properties, including the yield strength. In the last two decades, the dual-phase steels have been used in the automotive industry to improve the impact resistance of components and reduce the total weight of the car body [4-6]. In addition to these advantages, the dual-phase steels also have good weldability, fatigue crack growth resistance and high deformation hardening coefficient. Due to their high energy absorption and fatigue strength, dual-phase steels are suitable for the production of structural and safety parts in the automotive industry, such as cross beams, longitudinal beams and reinforcements $[7,8]$. The HSLA steel is a well-known type of steel alloy that provides many benefits over regular steel alloys. In general, the HSLA alloys are much stronger than mild steels. The low-alloy steel has good machinability and hardenability properties. The grain refinement and precipitation hardening improve 
the strength of HSLA steels; therefore, they are suitable for car body applications. The elements such as $\mathrm{Ti}$ and $\mathrm{Nb}$ form precipitates that control grain growth and cause precipitation strengthening $[9,10]$. Most HSLA steels are supplied in the as-hot-rolled condition with ferritic-pearlitic microstructure. Pearlite is generally an undesirable strengthening factor in structural steels, because it reduces the impact toughness and requires higher carbon contents. Moreover, yield strength is largely unaffected by a higher pearlite content. The ferrite in the HSLA steels is typically strengthened by grain refinement, precipitation hardening, and, to a lesser extent, solid-solution strengthening [11,12].

Resistance spot welding (RSW) is one of the best known and most used methods of joining high-strength steels. RSW has been commonly used in the automobile industry. RSW is a technology that produces a weld without filler metal by means of a high-intensity current, under simultaneous pressure application $[13,14]$. This process is described as the heat generated by the welding current used to reach the temperature required for the welding of two or more materials, while the resistance at the welding site is applied. One of the advantages of this technology is high process intensity. The strength of resistance spot welds depends on the welding parameters and the type of materials. The parameters of resistance spot welding are the welding time, the welding current and the pressing force of the electrodes [15-17].

In many cases, the material is surface treated, for example the material is galvanized with zinc. Because of this, a different kind of material joining technology has to be used to join the sheets. For this reason, other joining processes have been developed, such as mechanical joining - clinching. In the last decade, clinching has developed rapidly as a technology for joining the metal sheets. Compared with the resistance spot welding, there are many advantages of the mechanical clinching process, such as no spark and lower running time. There is no thermal chemical reaction in the clinching process $[18,19]$. A mechanical interlock is formed because of the plastic deformation of the sheets. The principle of clinching consists in interlocking the materials to be joined together using a punch and a die. The material at the joint is reinforced because of the process of clinching and the surface of the materials does not have to be cleaned before the joining process [20-22].
The paper deals with the evaluation of the joints made by resistance-spot welding and clinching on the HCT600X+ZF, HCT600X $+\mathrm{Z}$ and HX420LAD high-strength steel sheets.

\section{MATERIALS AND METHODS}

\section{Used materials}

In the experiment, three types of materials were used. They are advanced high-strength steels. These steels are marked as HCT600X+Z, HCT600X+ZF and HX420LAD. The thickness of all tested steel sheets was $1.5 \mathrm{~mm}$. Two types of coating were used in the HCT600X steel sheet. The first one (marked as " $Z$ ") was a zinc coating, so this sheet was hot-dip galvanized on both sides. The second one (marked as "ZF") is a zinc-iron alloy coating, which provides better corrosion protection than pure zinc [23]. The HX420LAD+Z steel sheet was hot-dip galvanized on both sides. Table 1 shows the basic mechanical properties. The chemical composition of the steel sheets is shown in Table 2.

The dimensions of the test specimen are defined by STN 05 1122. After cutting the samples

Table 1. Basic mechanical properties of the observed materials

\begin{tabular}{|l|c|c|c|c|}
\hline \multicolumn{1}{|c|}{ Material } & $\begin{array}{c}\text { Thickness } \\
{[\mathrm{mm}]}\end{array}$ & $\begin{array}{c}\mathrm{Rp}_{0,2} \\
{[\mathrm{MPa}]}\end{array}$ & $\begin{array}{c}\mathrm{Rm} \\
{[\mathrm{MPa}]}\end{array}$ & $\mathrm{A}_{80}[\%]$ \\
\hline HCT600X+Z & 1.5 & 373 & 606 & 24.8 \\
\hline HCT600X+ZF & 1.5 & 369 & 633 & 22.5 \\
\hline HX420LAD+Z & 1.5 & 490 & 565 & 19.5 \\
\hline
\end{tabular}

Table 2. Chemical composition of the observed materials $(\% \mathrm{wt})$

\begin{tabular}{|c|c|c|c|c|c|}
\hline Material & \multicolumn{5}{|c|}{ Chemical composition } \\
\hline \multirow{4}{*}{ HCT600X+ZF } & $\mathrm{C}$ & $\mathrm{Mn}$ & $\mathrm{Si}$ & $\mathrm{P}$ & $\mathrm{Al}$ \\
\cline { 2 - 6 } & 0.080 & 1.78 & 0.01 & 0.014 & 0,045 \\
\cline { 2 - 6 } & $\mathrm{Nb}$ & $\mathrm{Ti}$ & $\mathrm{V}$ & $\mathrm{Mo}$ & $\mathrm{Cr}$ \\
\cline { 2 - 6 } HCT600X+Z & 0.002 & 0.001 & 0.002 & 0.179 & 0.211 \\
\hline & $\mathrm{C}$ & $\mathrm{Mn}$ & $\mathrm{Si}$ & $\mathrm{P}$ & $\mathrm{Al}$ \\
\cline { 2 - 6 } & 0.09 & 1.89 & 0.26 & 0.014 & 0.026 \\
\cline { 2 - 6 } & $\mathrm{Nb}$ & $\mathrm{Ti}$ & $\mathrm{V}$ & $\mathrm{Mo}$ & $\mathrm{Cr}$ \\
\cline { 2 - 6 } & 0.001 & 0.003 & 0.002 & 0.002 & 0.21 \\
\hline \multirow{5}{*}{ HX420LAD+Z } & $\mathrm{C}$ & $\mathrm{Mn}$ & $\mathrm{Si}$ & $\mathrm{P}$ & $\mathrm{Al}$ \\
\cline { 2 - 6 } & 0.09 & 1.2 & 0.02 & 0.016 & 0.035 \\
\cline { 2 - 6 } & $\mathrm{Nb}$ & $\mathrm{Ti}$ & $\mathrm{V}$ & $\mathrm{Mo}$ & $\mathrm{Cr}$ \\
\cline { 2 - 6 } & 0.0055 & 0.015 & - & - & - \\
\hline
\end{tabular}


from the metal sheet to a size of $40 \times 90 \mathrm{~mm}$, with the overlap length of $30 \mathrm{~mm}$. The same sample sizes were used for all 3 joint types.

This dimension is also defined by the above-mentioned standard to determine the position of the joints produced by the clinching and resistance spot welding. Since the sheets of metal are conserved after manufacturing, the preparation of the samples involved cleaning and degreasing before the resistant spot welding process. Acetone was applied for cleaning surfaces before welding. It was not necessary to clean the samples before clinching. Figure 1 shows a test sample according to STN 051122.

\section{Resistance spot welding}

Resistance spot welding was carried out under laboratory conditions by means of a pneumatic spot welding machine BPK 20 . The $\mathrm{Cu}-\mathrm{Cr}$ welding electrodes according to the EN 423039.71 standard were used for resistance spot welding. A new pair of welding electrodes was used for each type of high-strength steel sheet to prevent the wear of the welding tips. The working surfaces of the welding electrodes were $\varnothing 5 \mathrm{~mm}$ with a conical end.

For each type of sheet, 4 groups of samples were created: A, B, C, D. Each group contains 6 samples. The welding current $\mathrm{I}_{4}$ is the welding current. Tables $3-5$ below shows the welding parameters used for $\mathrm{HCT} 600 \mathrm{X}+\mathrm{Z}$, HCT $600 \mathrm{X}+\mathrm{ZF}$ and HX420LAD $+Z$. Figure 2 shows the created resistant spot welds on the investigated materials.

\section{Clinching}

The clinching method is a relatively new method of joining materials. The principle of clinching consists in interlocking the materials to be joined together using a punch and a die. At the moment of contact of the material and the die, the material flow to the sides and creates a joint $[24,25]$.

The hydraulic press machine ZD 40 with the load range of 40,200 and $400 \mathrm{kN}$ was used for clinching. Figure 3 shows the clinching tool used in experiments. A punch with the diameter of $\varnothing 5 \mathrm{~mm}$ and a die with the diameter of $\varnothing 8 \mathrm{~mm}$ were used for all types of high-strength steel sheets. The parameters of clinching are described in Table 6. Figure 4 shows the samples with the joints made by clinching technology. As with welding, 6 samples for each type of steel sheet were joined by clinching.

\section{Tensile test}

In the experiment, the load-bearing capacity of resistance spot welded joints and clinched joints were measured. The test was carried out on TIRAtest 2300 . The measuring range of the device is from $0.8 \mathrm{kN}$ to $100 \mathrm{kN}$ with a load (traverse) speed of $10 \mathrm{~mm} / \mathrm{min}$. During the test, the ambient temperature is within the range of 10$35^{\circ} \mathrm{C}$. The tensile test was carried out in accordance with STN 051122 on two types of joints.

The gradual loading of test specimens created by welding and mechanical joining results in partial elongation or breakage. Subsequently, the maximum applied force Fmax was measured till the rupture occurred. The results of the tensile test for welded joints also included the evaluation of the type of failure - fusion welded joint or cold welded joint. In the case of the samples produced by mechanical joining, the failure mechanisms were evaluated too. These mechanisms include pull out mode, neck fracture mode, neck fracture with plastic deformation mode and pull out with neck fracture mode.

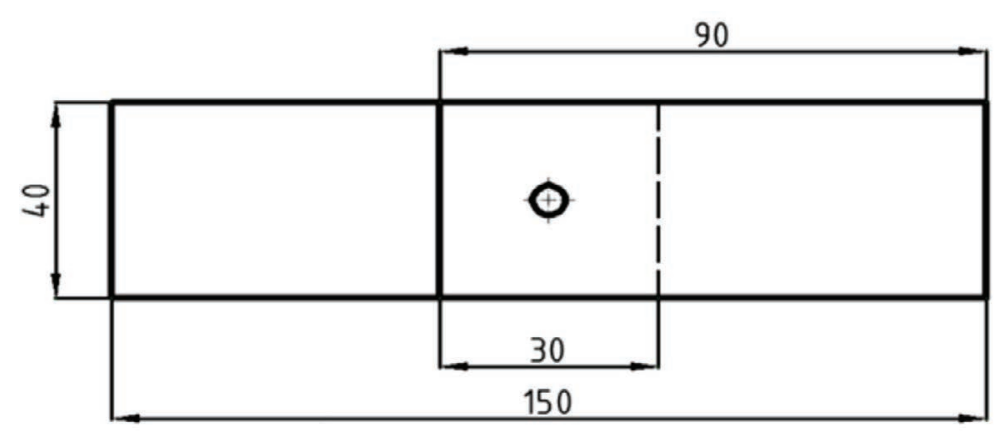

Figure 1. Sample dimensions for tensile test 
Table 3. Welding parameters used for the HCT600X $+Z$ material

\begin{tabular}{|c|c|c|c|}
\hline \multirow[b]{2}{*}{ HCT600X+Z } & \multicolumn{3}{|c|}{ Welding parameters } \\
\hline & $\begin{array}{c}\text { Force Fz } \\
{[\mathrm{kN}]}\end{array}$ & $\begin{array}{c}\text { Welding } \\
\text { Current } \mathrm{I}_{4} \\
{[\mathrm{kA}]}\end{array}$ & $\begin{array}{c}\text { Time Tw [per.] } \\
\text { (1 per. }=0.02 \mathrm{~s})\end{array}$ \\
\hline$A$ & 9.0 & 6 & 15 (300 ms) \\
\hline $\mathrm{B}$ & 9.0 & 6.5 & 15 (300 ms) \\
\hline $\mathrm{C}$ & 9.0 & 7 & 15 (300 ms) \\
\hline $\mathrm{D}$ & 9.0 & 7.5 & 15 (300 ms) \\
\hline
\end{tabular}

Table 5. Welding parameters used for the HX420LAD $+Z$ material

\begin{tabular}{|c|c|c|c|}
\hline \multirow[b]{2}{*}{ HX420LAD+Z } & \multicolumn{3}{|c|}{ Welding parameters } \\
\hline & $\begin{array}{l}\text { Force Fz } \\
{[\mathrm{kN}]}\end{array}$ & $\begin{array}{c}\text { Welding } \\
\text { Current I } \\
{[\mathrm{kA}]}\end{array}$ & $\begin{array}{l}\text { Time Tw [per.] } \\
(1 \text { per. }=0.02 \mathrm{~s})\end{array}$ \\
\hline$A$ & 6.0 & 5.5 & 15 (300 ms) \\
\hline B & 6.0 & 6 & 15 (300 ms) \\
\hline C & 6.0 & 6.5 & 15 (300 ms) \\
\hline D & 6.0 & 7 & 15 (300 ms) \\
\hline
\end{tabular}

Table 4. Welding parameters used for the HCT600X+ZF material

\begin{tabular}{|c|c|c|c|}
\hline \multirow[b]{2}{*}{ HCT600X+ZF } & \multicolumn{3}{|c|}{ Welding parameters } \\
\hline & $\begin{array}{c}\text { Force Fz } \\
{[\mathrm{kN}]}\end{array}$ & $\begin{array}{c}\text { Welding } \\
\text { Current } \mathrm{I}_{4} \\
{[\mathrm{kA}]}\end{array}$ & $\begin{array}{l}\text { Time Tw [per.] } \\
(1 \text { per. }=0.02 \mathrm{~s})\end{array}$ \\
\hline A & 9.0 & 5 & 15 (300 ms) \\
\hline B & 9.0 & 5.5 & 15 (300 ms) \\
\hline $\mathrm{C}$ & 9.0 & 6 & 15 (300 ms) \\
\hline $\mathrm{D}$ & 9.0 & 6.5 & 15 (300 ms) \\
\hline
\end{tabular}

\section{Metallographic observation}

In this analysis, the changes in the microstructure of HCT600X $+\mathrm{Z}, \mathrm{HCT} 600 \mathrm{X}+\mathrm{ZF}$ and HX420LAD $+Z$ materials, which took place during the formation of welded joints, were observed. Interlocking, the thickness of the bottom of the joint, the thickness of the neck of the joint as well as the defects of the joints formed by the clinching were observed too.

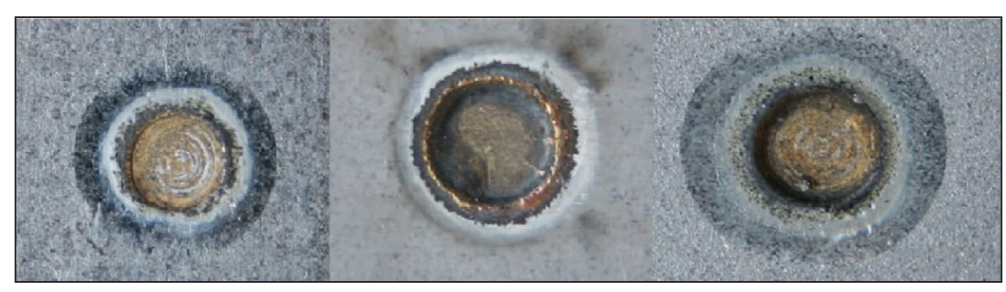

Figure 2. Created resistance spot welds on the investigated materials: a) HCT600X+Z; b) HCT600X+ZF and c) HX420LAD +Z

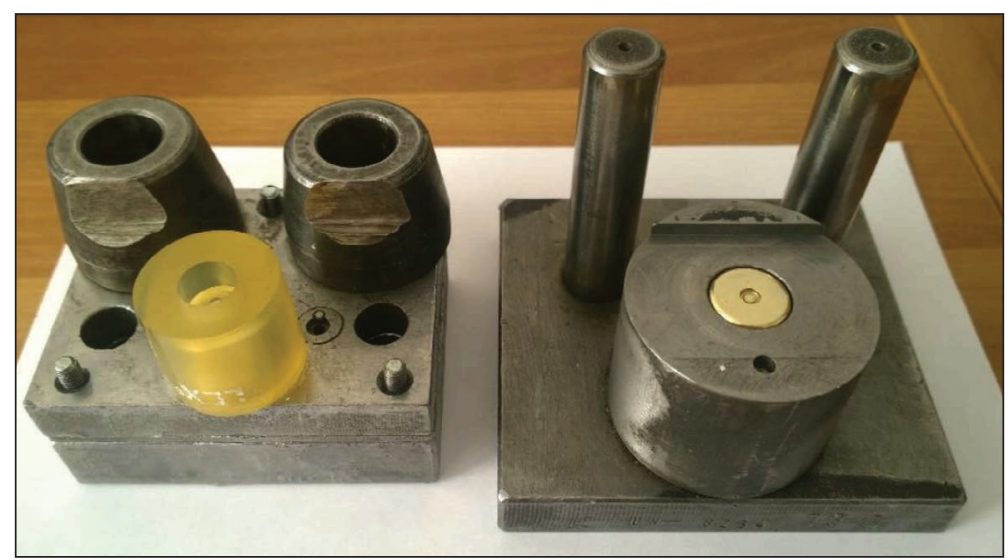

Figure 3. A tool for creating joints using the clinching method

Table 6. Parameters of clinching

\begin{tabular}{|l|c|c|c|c|}
\hline \multicolumn{1}{|c|}{ Material } & Number of joined sheets & Pressing force F $[\mathrm{kN}]$ & Punch diameter & Die diameter \\
\hline HCT600X+Z $(1.5 \mathrm{~mm})$ & 2 & 70 & $\varnothing 5 \mathrm{~mm}$ & $\varnothing 8 \mathrm{~mm}$ \\
\hline HCT600X+ZF $(1.5 \mathrm{~mm})$ & 2 & 70 & $\varnothing 5 \mathrm{~mm}$ & $\varnothing 8 \mathrm{~mm}$ \\
\hline HX420LAD+Z $(1.5 \mathrm{~mm})$ & 2 & 60 & $\varnothing 5 \mathrm{~mm}$ & $\varnothing 8 \mathrm{~mm}$ \\
\hline
\end{tabular}




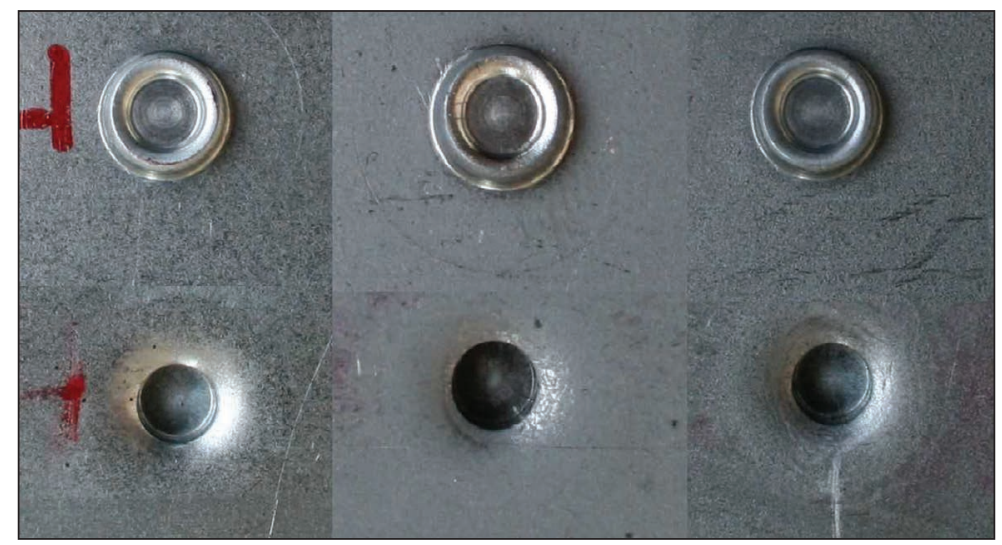

Figure 4. Sample joints created by clinching: a) HCT600X+Z; b) HCT600X+ZF and c) HX420LAD $+Z$

A microscopic analysis of metallographic cross-sections was performed by using a KEYENCE VHX- 5000 light optical microscope.

In the case of the joints formed by resistance spot welding, the structure of the weld, the occurrence of pores, cracks, the presence of impurities or the cleanliness of the contact surfaces can be evaluated.

\section{ANALYSIS OF ACHIEVED RESULTS}

\section{Results of tensile test}

The research related to the resistance spot welding allowed evaluating the influence of welding current on the load-bearing capacity of observed materials. The value of the welding current influences the formation of an appropriate weld nugget $[13,26]$.

The tensile test was performed on the samples in order to determine the static behaviour of the joints and to estimate their load-bearing capacity. The maximum shearing load was the most significant value obtained from the "load-displacement"

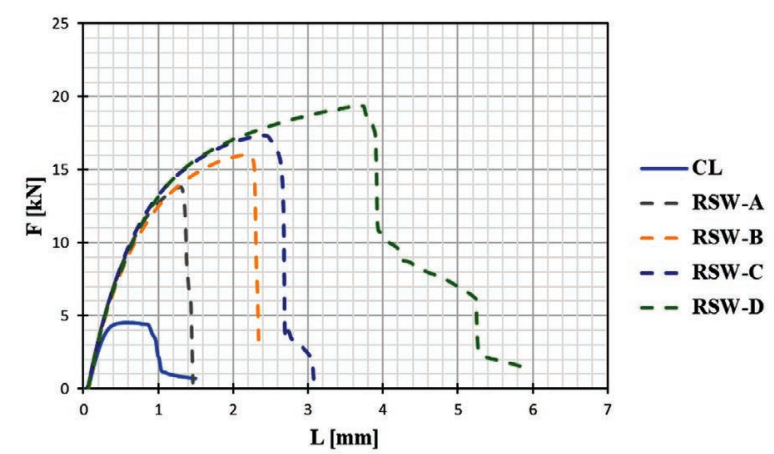

Figure 5. Load-displacement curves for the HCT600X $+Z$ material curves as shown in Figure 5-7. The form of the curves shows the behaviour of the clinched joints under loading, especially the capacity for deformation. In this case, the maximum shearing load for material $\mathrm{HCT} 600 \mathrm{X}+\mathrm{Z}$ was measured on the RSW-D sample (around $19.5 \mathrm{kN}$ ) with the corresponding displacement about $3.8 \mathrm{~mm}$. The average minimum shearing load for the HCT $600 \mathrm{X}+\mathrm{Z}$ material was measured on the CL sample (around $4.5 \mathrm{kN}$ ) with the corresponding displacement of about $1.9 \mathrm{~mm}$.

The maximum shearing load for the HCT $600 \mathrm{X}+\mathrm{ZF}$ material was measured on the RSW-D sample (around $18.7 \mathrm{kN}$ ) with the corresponding displacement of about $2.25 \mathrm{~mm}$. The average minimum shearing load for the HCT $600 \mathrm{X}+\mathrm{Z}$ material was measured on the CL sample (around $6 \mathrm{kN}$ ) with the corresponding displacement of about $0.5 \mathrm{~mm}$.

The maximum shearing load for material HX420LAD $+Z$ was measured on the RSW-D sample (around $16.2 \mathrm{kN}$ ) with the corresponding displacement of about $2.5 \mathrm{~mm}$. The average minimum shearing load for the $\mathrm{HCT} 600 \mathrm{X}+\mathrm{Z}$ material was measured on the CL sample (around $4 \mathrm{kN}$ )

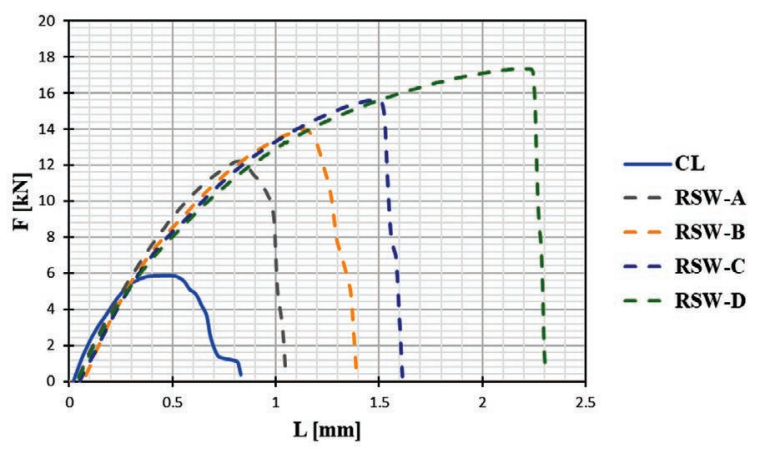

Figure 6. Load-displacement curves for the HCT600X+ZF material 


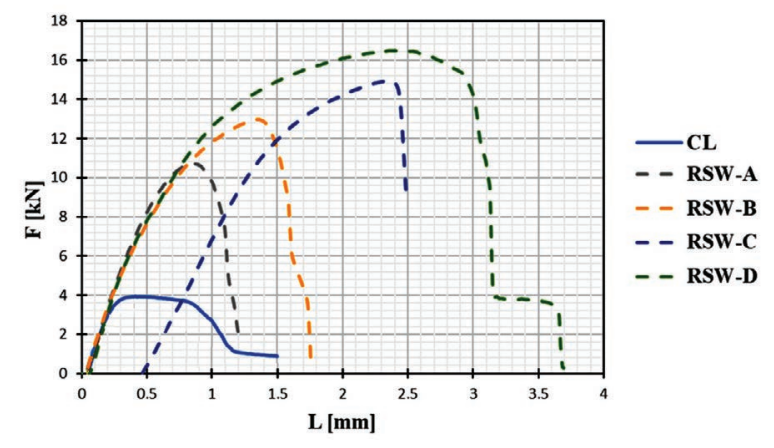

Figure 7. Load-displacement curves for the HX420LAD +Z material

with the corresponding displacement of about $0.4 \mathrm{~mm}$.

Figures 8-10 show the average values of the force Fmax measured during the tensile test for the individual methods of the realized joints. The figures show that the clinched joints achieved the minimum values of load-bearing capacity in all tested materials. The maximum values of load-bearing capacity were measured in the samples with spot welds, made with the highest values of welding current I.

The lowest value of load-bearing capacity of the joints after the tensile test for all observed materials were measured on the CL samples: about $4.9 \mathrm{kN}$ on the samples with the HCT600X $+\mathrm{Z}$ steels, about $5.9 \mathrm{kN}$ on the samples with the HCT600X+ZF steels and about $4 \mathrm{kN}$ on the samples with the HX420LAD $+Z$ steels.

The highest value of load-bearing capacity of joints were measured on the resistance spot welded samples with the highest values of welding current (samples D): about $19.5 \mathrm{kN}$ on the samples with HCT600X $+Z$, about $17 \mathrm{kN}$ on the samples with HCT600X+ZF and about $16.5 \mathrm{kN}$ on the samples with HX420LAD+Z.

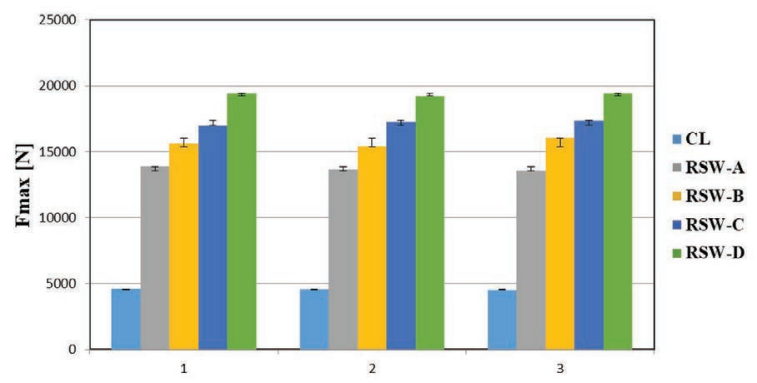

Figure 8. Graph of average values of load-bearing capacity of joints after the tensile test for the HCT $600 \mathrm{X}+\mathrm{Z}$ material.

(CL - clinching, RSW - resistance spot welding)
As shown in Figure 11, only one type of joint occurred in all examined spot welded joints - fusion welded joint.

\section{Results of metalographic observation}

Metallographic observation of clinched joints was performed on all the observed material, i.e. HCT600X $+\mathrm{Z}, \mathrm{HCT} 600 \mathrm{X}+\mathrm{ZF}$ and HX420LAD $+Z$, as is shown in Figures 12-14.

Figure 12-14(a) show the macrostructure of a clinched joint of observed steel sheets. The clinched joints were created without any cracks or failures. The typical areas of mechanical interlock and well-formed parts of bottom of clinched joints with typical shape of groove die are visible in Figures 12-14(b, c).

Since only the welding current parameter changed in the experiment, two samples with spot welds of group A and group D were selected. Group A represents the value of the lowest welding current for each high-strength steel sheet and group D represents the values of the highest welding current. Microscopic observation was used to assess the occurrence of cracks and pores, whether it is a cold or fusion joint. The quality of welded joints can be assessed by means of a macrostructure on metallographic sections.

The resistance spot welded joints made on the sample with the HCT600X $+Z$ steel sheets are shown in Figures 15 and 16. Figure 15a shows a spot weld made with the lowest value of welding current. The fusion spot weld with characteristic areas defined as [28]: base material, heat affected zone and weld nugget was observed. Figure $15 \mathrm{~b}$ shows the transition from the heat affected zone to the basic structure of the HCT600X $+\mathrm{Z}$ steel sheet. Figure $15 \mathrm{c}$ shows the formation of a

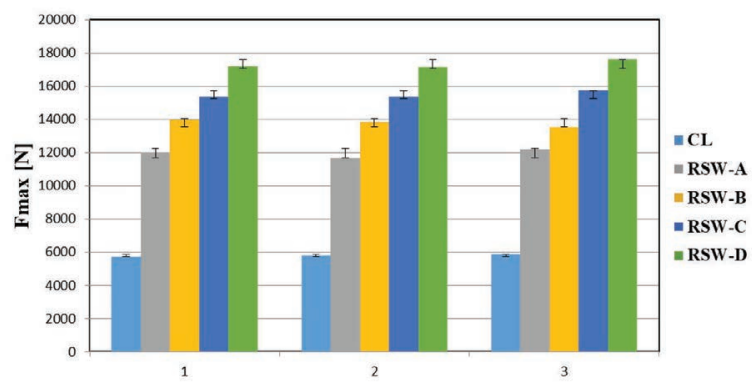

Figure 9. Graph of average values of load-bearing capacity of joints after the tensile test for the HCT600X+ZF material.

(CL - clinching, RSW - resistance spot welding 


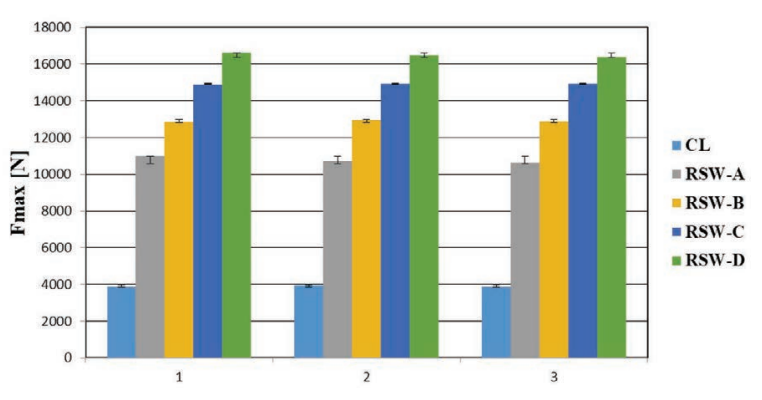

Figure 10. Graph of average values of load-bearing capacity of joints after the tensile test for the $\mathrm{HX} 420 \mathrm{LAD}+\mathrm{Z}$ material

(CL - clinching, RSW - resistance spot welding)

dendritic structure in the core of the weld nugget with a typical martensitic structure.

Figure 16a shows a spot weld made on the HCT600X $+Z$ steel sheets with the highest value of welding current (sample D). The grains in the weld nugget grown significantly in the current flow direction. The transition from the heat-affected weld area to the basic structure of the material and the interface of the joined sheets can be observed in Figure 16b. The significant porosity in the weld metal structure caused by the high welding current of the sample D as well as significant marks of the welding electrode tips were observed (Figure 16c).

Figures 17 and 18 show the spot welded joints made on the sample with the HCT600X+ZF steel sheets. The sample with the fusion spot welded joint made with the lowest value of welding current is shown in Figure 17a. The spot welded joint with its characteristic parts is clearly visible. Figure $17 \mathrm{~b}$ shows the interface of the joined materials which passes into the heat affected zone, then to the weld nugget. The lack of fusion caused by the shrinkage of weld metal can be seen in the micrograph in Figure 17c.

The sample D with the HCT600X+ZF steel sheets made with the highest value of welding current is shown in Figure 18. The grains in the weld nugget grown significantly in the current flow direction. All the typical parts of spot weld can be find as well (Figure 18b,c). A lot of pores are visible in the weld nugget. Due to the value of welding current, significant marks of electrode tips occurred (Figure 18a). The weld nugget size did not grow as rapidly as in spot welds with the HCT $600 \mathrm{X}+\mathrm{Z}$ materials. On the other hand, cracks in the heat affected zone occurred - Figure 18d,e. .These hot cracks were formed during solidification of the liquid nugget [26].

The samples with spot welded joints made on the HX420LAD $+Z$ steel sheets with the lowest and the highest values of welding current are shown in Figures 19 and 20. The use of the lowest value of the welding current led to the forming of the typical fusion welded joint as well (Figure 19). No defects such as pores, cracks or lack of fusion occurred - see Figure 19b,c.

The highest value of the welding current applied to the sample D with HX420LAD $+Z$ sheets led to significant porosity in the weld nugget and the heat affected zone as well (Figure 20a-c). Excessive heating due to the highest value of welding current caused excessive marks of electrode tips on the surfaces of welded sheets (Figure 20a). The hot cracks in the heat affected zone formed during solidification of the liquid nugget occurred - see Figure 20d,e.
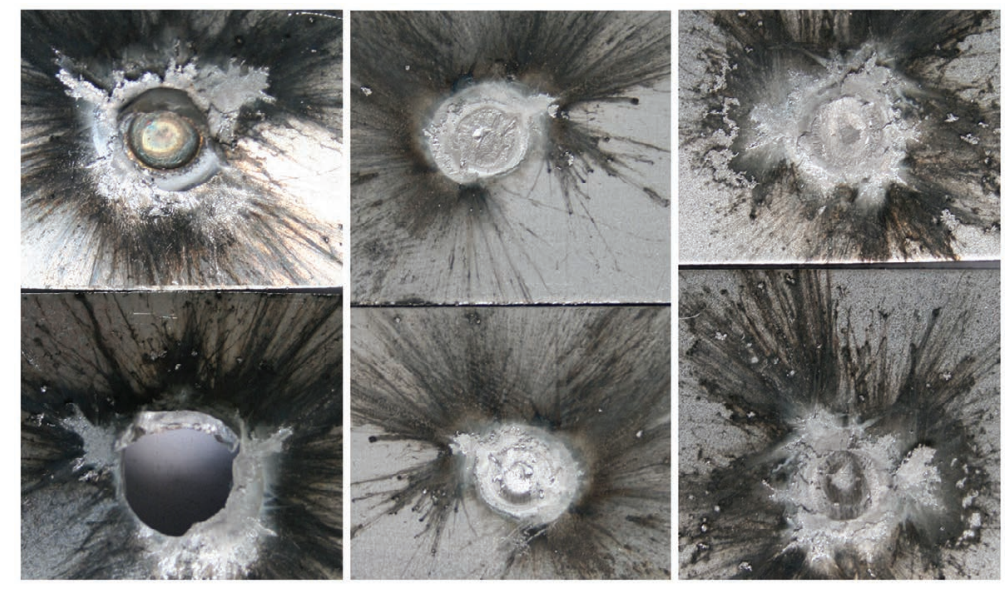

Figure 11. The samples with spot welded joints after the tensile test (samples $C$ ):

a) HCT600X+Z b) HCT600X+ZF and c) HX420LAD $+Z$ 


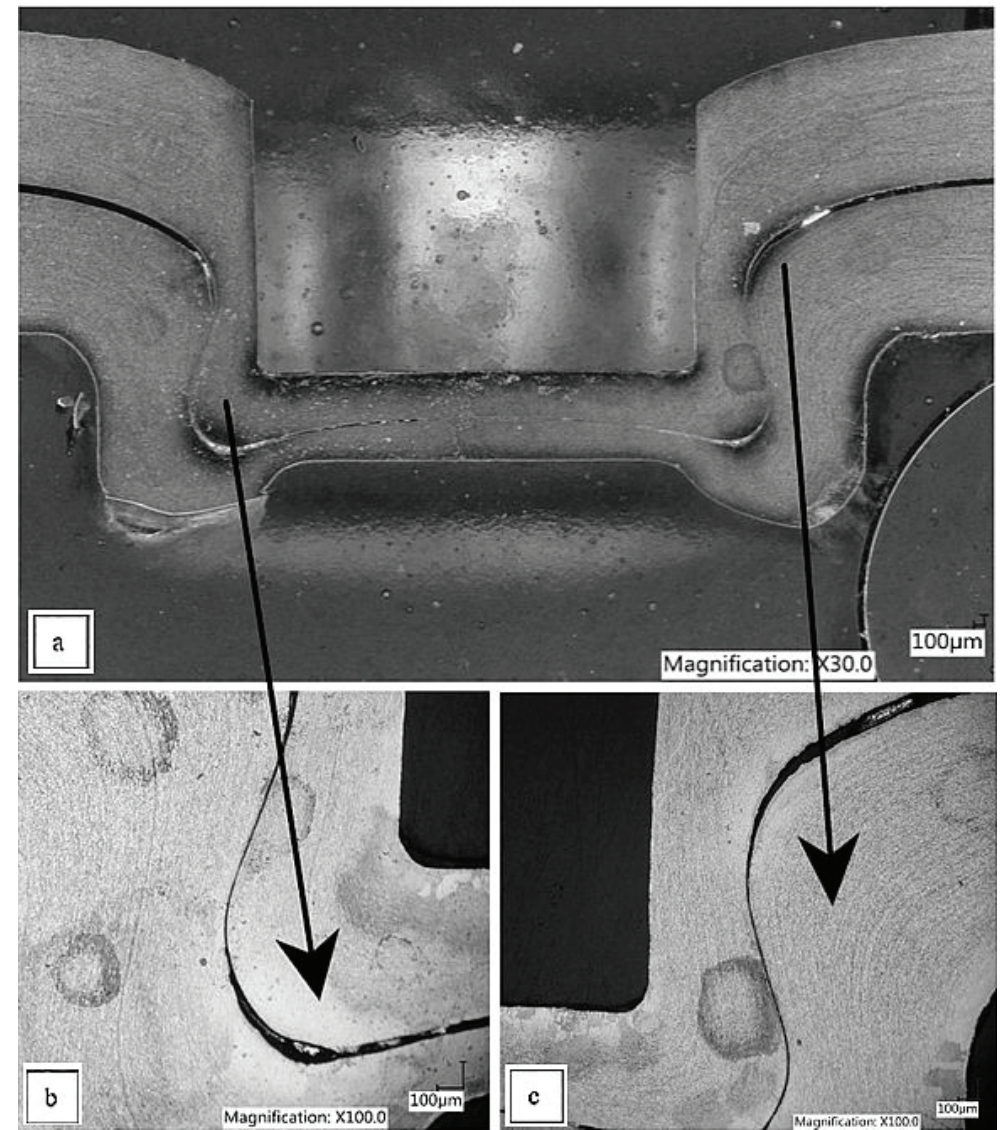

Figure 12. Macro and microstructure of the clinched joint made of HCT600X $+Z$

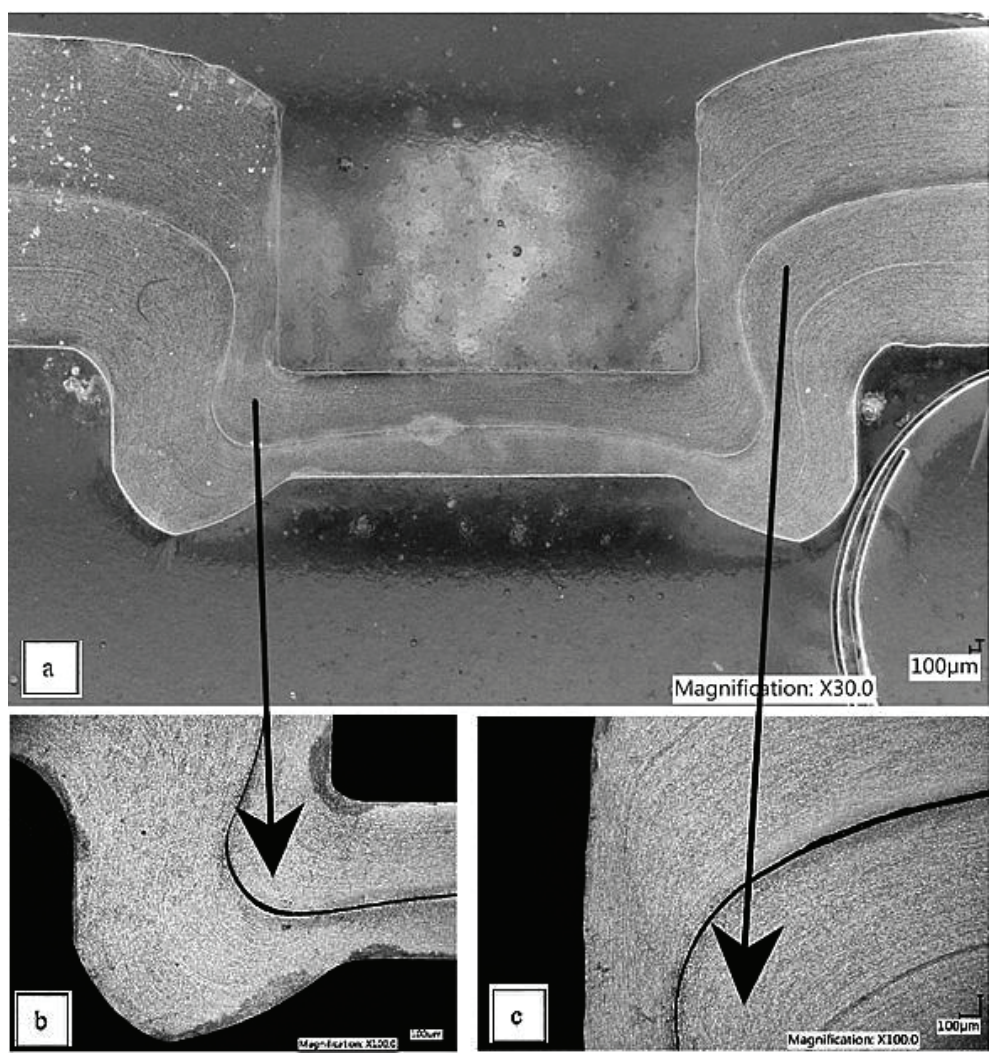

Figure 13. Macro and microstructure of the clinched joint made of HCT600X+ZF 


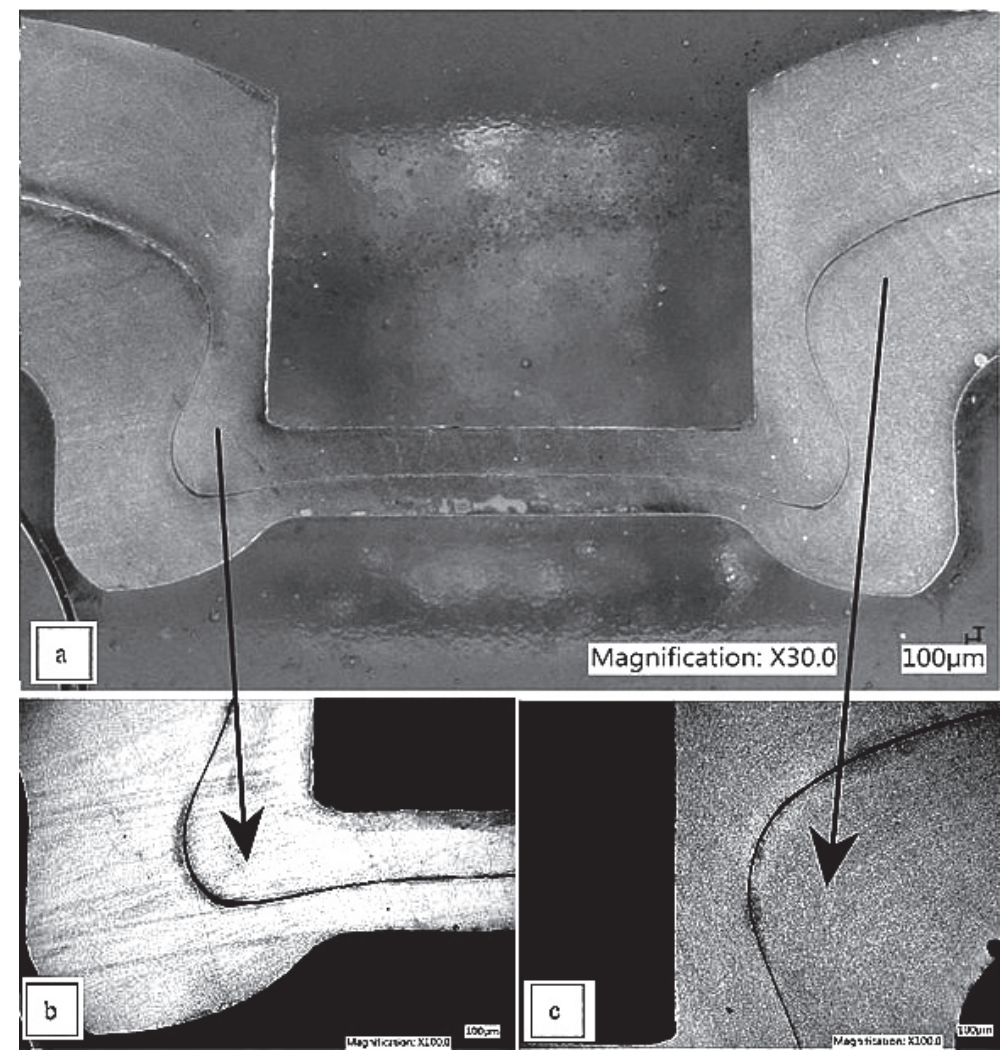

Figure 14. Macro and microstructure of HX420LAD $+Z$ clinched joint

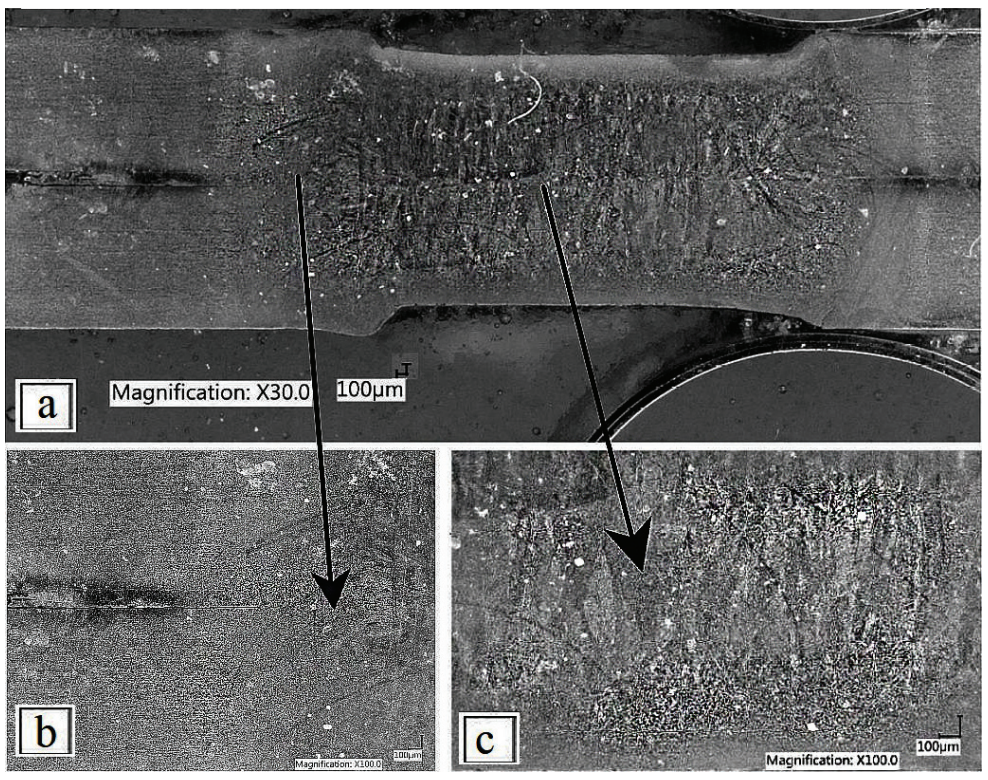

Figure 15. Macro and microstructure of a group A sample made of HCT600X+Z

\section{CONCLUSIONS}

The automotive industry is constantly emphasising the reduction of vehicle weight. The main reason is to reduce emissions and recycle used materials. On the basis of these requirements, new car concepts are constantly emerging, which are made of different materials.
The paper deals with the evaluation of the joinability of the HX420LAD $+Z$, HCT $600 X+Z$ and HCT600X+ZF high-strength steel sheets, where the methods such as resistance spot welding and clinching were investigated. On the basis of the results of the performed experiments, it can be stated: - When the clinching method was used for joining all the investigated materials, no defects 


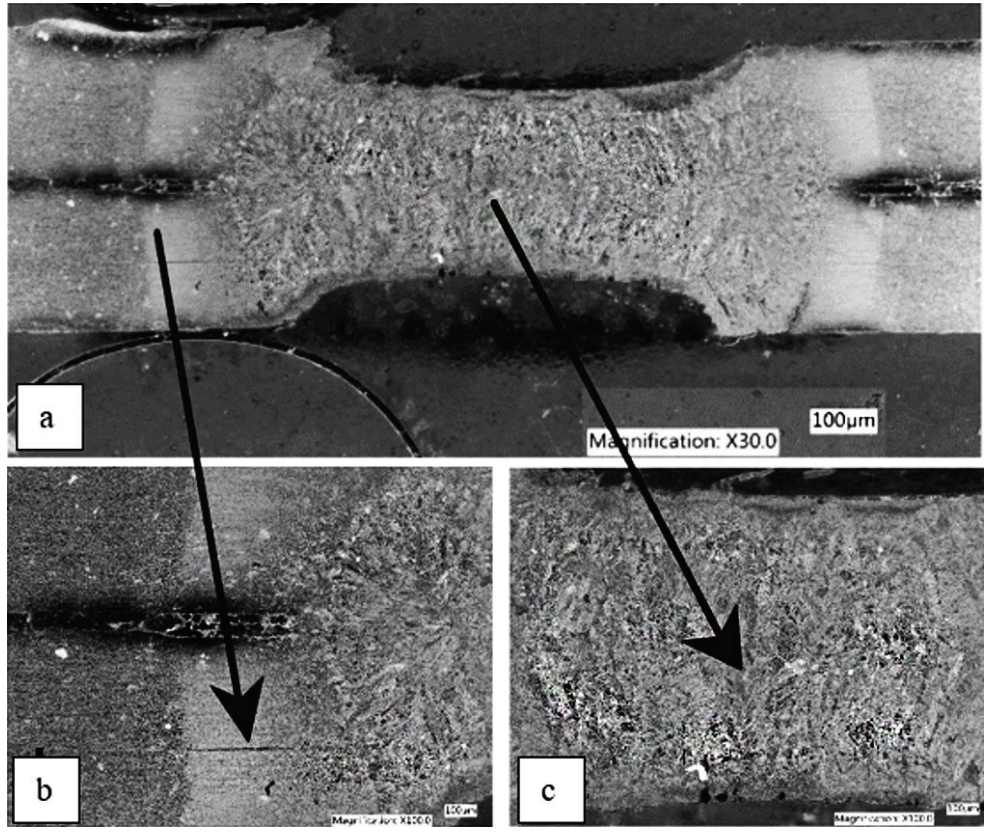

Figure 16. Macro and microstructure of a group D sample made of HCT600X $+Z$
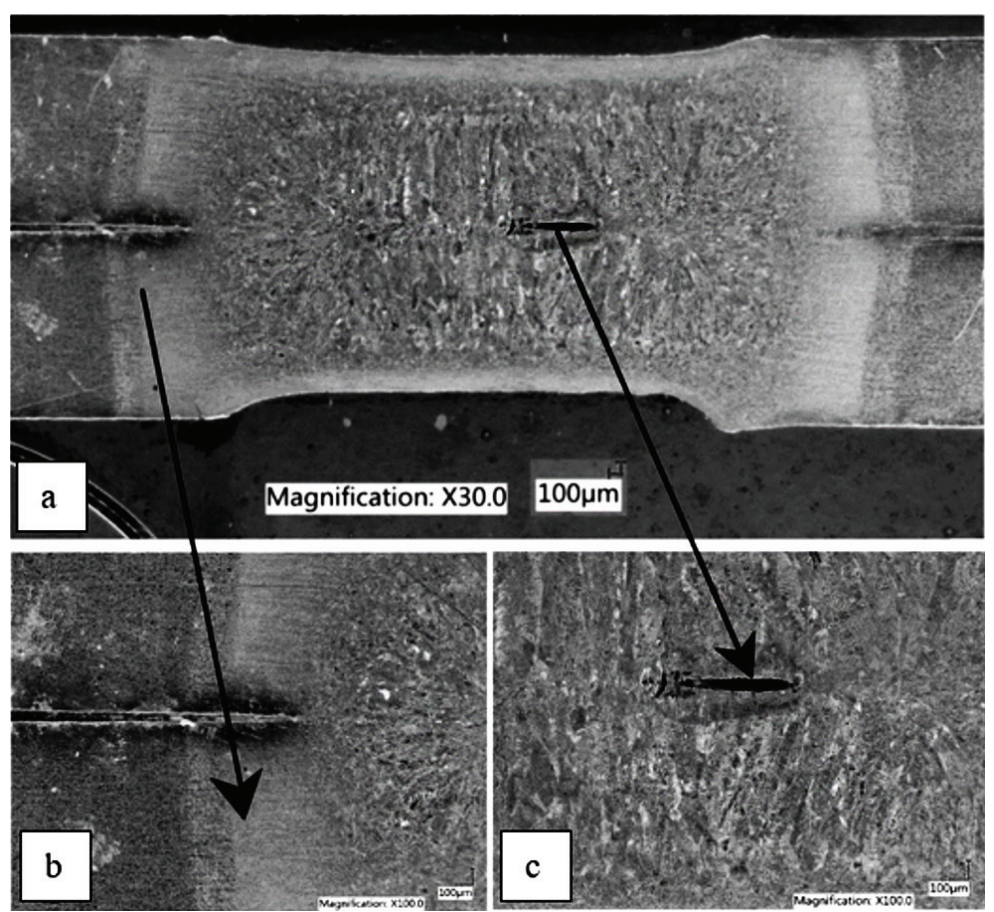

Figure 17. Macro and microstructure of a group A sample made of HCT600X+ZF.

such as cracks or failures were observed in the clinched joints.

- Welded joints without significant internal defects were observed in the samples of the joints made with the lowest welding current value.

- An increase of the welding current led to improved load-bearing capacity of the spot welded joints. However, when the highest values of welding current were used for making the joints, defects such as pores and lack of fusion in the weld nugget region as well as hot cracks in the heat affected zone occurred. As a further consequence of the use of high welding current values, the significant marks of the welding electrodes tips on the surfaces of samples with $\mathrm{HCT} 600 \mathrm{X}+\mathrm{Z}$ and $\mathrm{HX} 420 \mathrm{LAD}+\mathrm{Z}$ steel sheets were observed. These defects are unacceptable in terms of assessing the quality of spot welded joints. 

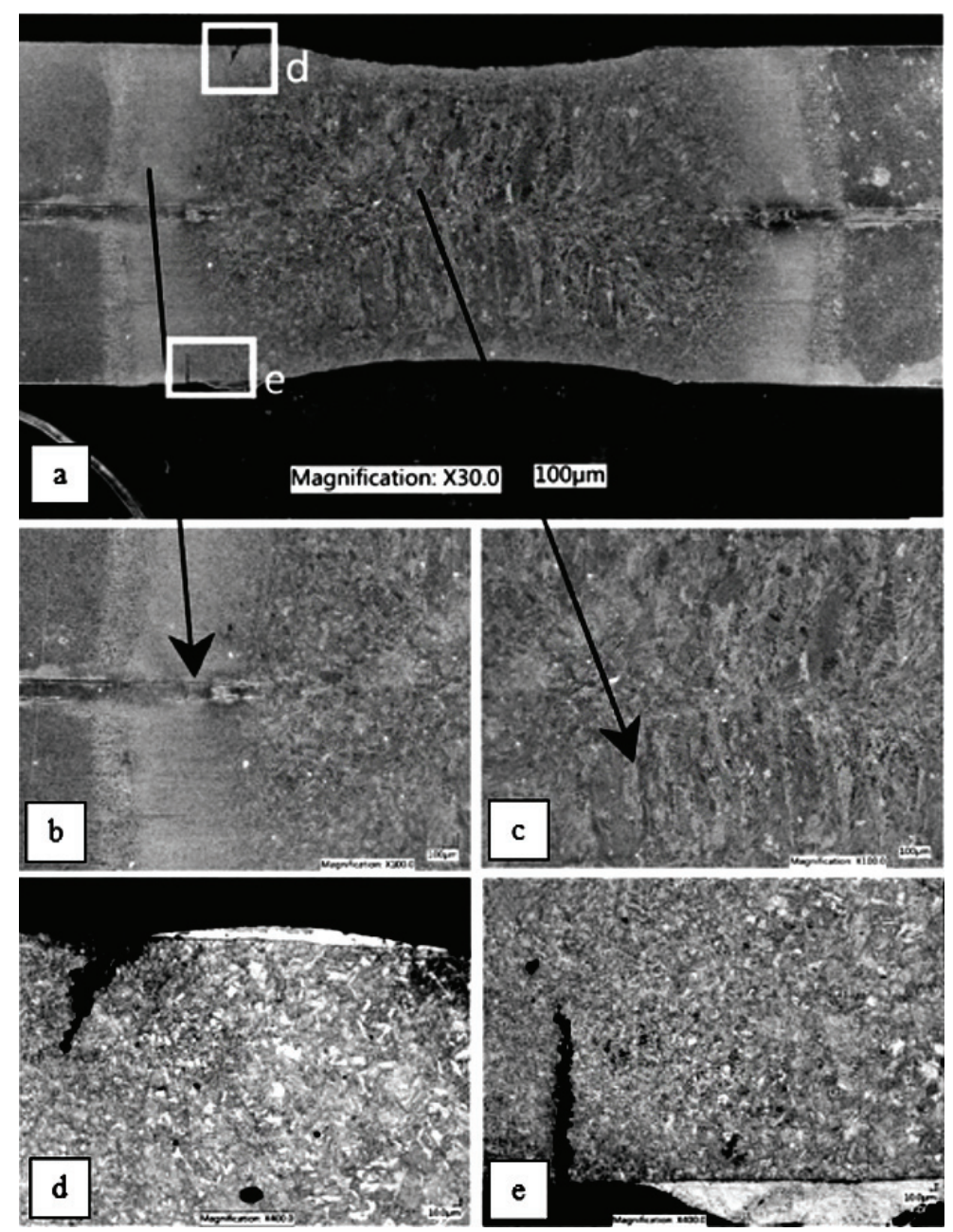

Figure 18. Macro and microstructure of a group D sample made of HCT600X+ZF.

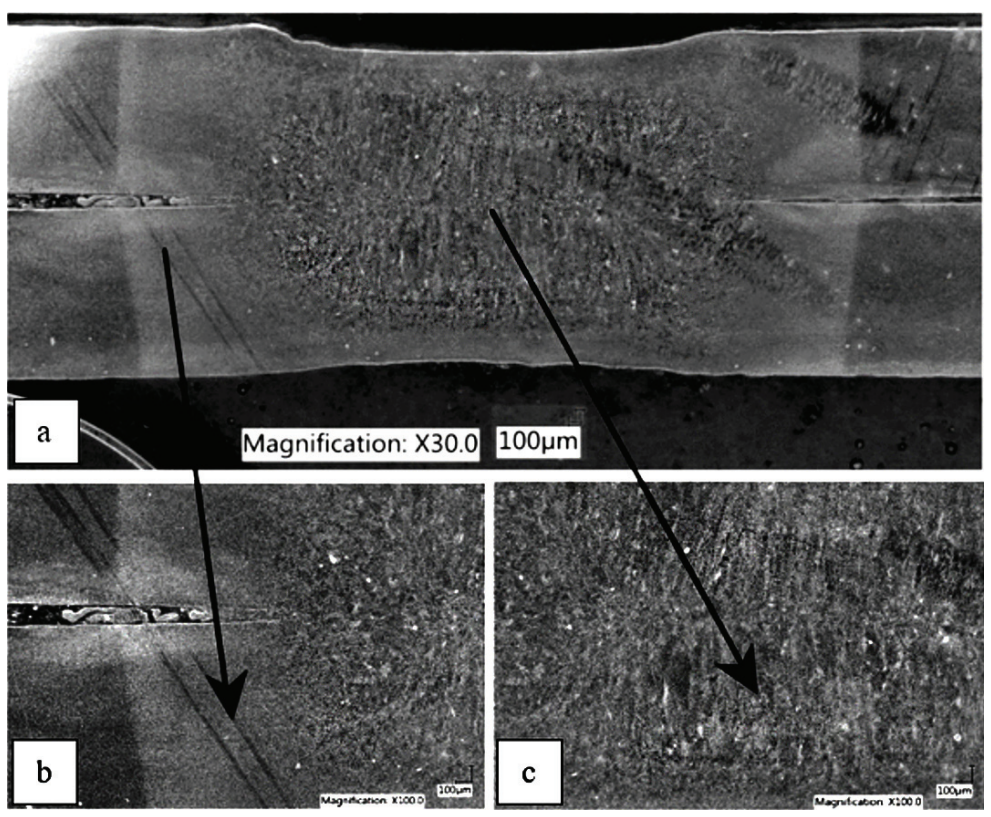

Figure 19. Macro and microstructure of a group A sample made of HX420LAD+Z. 


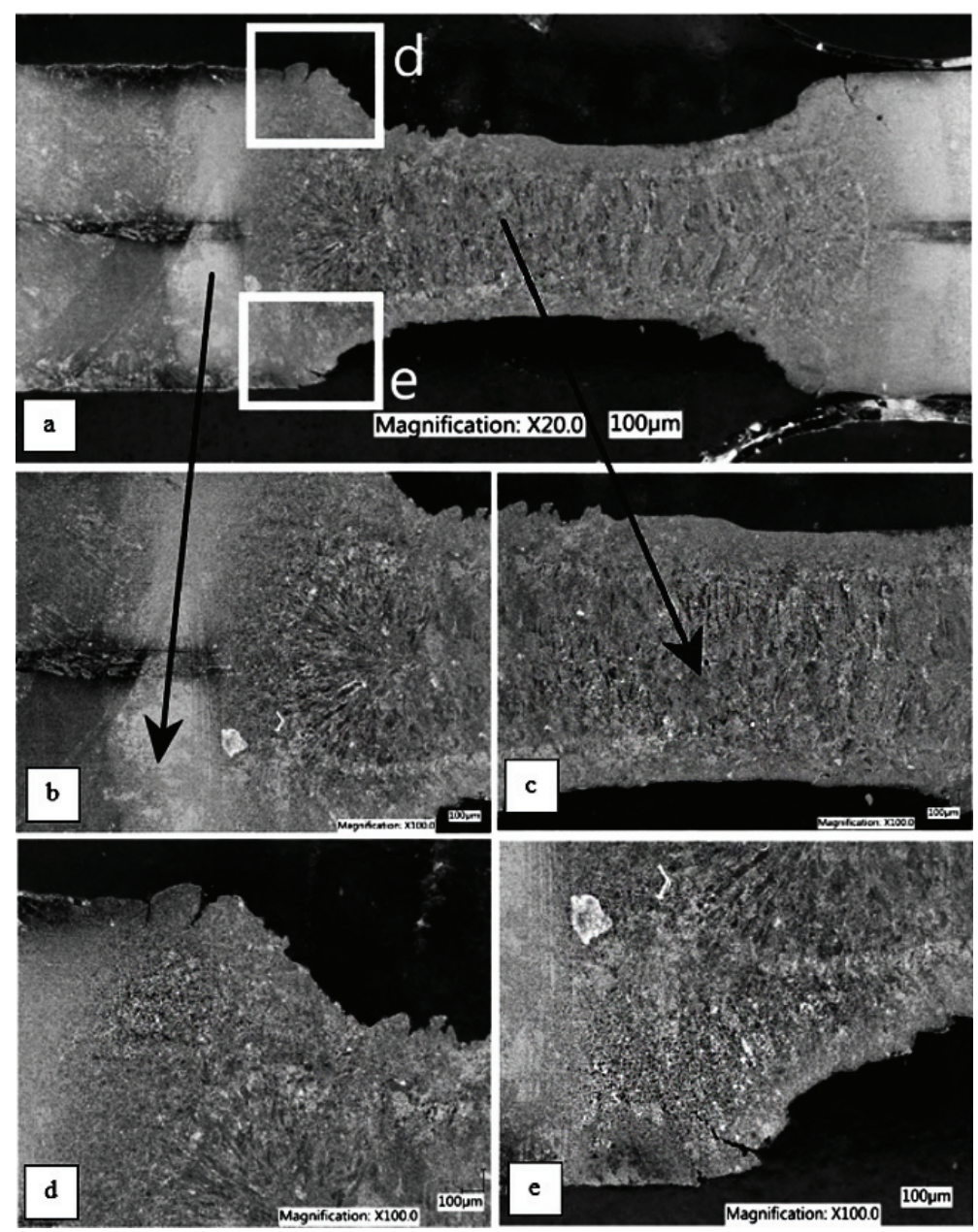

Figure 20. Macro and microstructure of a group D sample made of HX420LAD $+Z$.

- The clinched joints achieved an average of $32 \%$ (for $\mathrm{HCT} 600 \mathrm{X}+\mathrm{Z}$ ), $48 \%$ (for HCT $600 \mathrm{X}+\mathrm{ZF}$ ) and $36 \%$ (for HX $420 \mathrm{LAD}+\mathrm{Z}$ ) of load-bearing capacity compared to spot resistance welds. If the clinching method is taken as an alternative to resistance spot welding, it is necessary to increase the number of clinched joints to achieve a comparable load-bearing capacity.

- As the clinching method is a cold joining process, no metallurgical changes in the joined materials occurred. The clinching joints are classified as an environmentally friendly joining technology. They are less harmful to the environment, especially when joining hot-dip galvanized steel sheets.

\section{Acknowledgements}

This work was supported by the project APVV-17-0381 and the project VEGA No. $1 / 0441 / 17$.

\section{REFERENCES}

1. Adamczyk J., Grajcar A. Structure and mechanical properties of DP-type and TRIP-type sheets obtained after the thermomechanical processing. Journal of Materials Processing Technology. 2005; 162-163: 267-274.

2. Bleck W. Cold-rolled, high-strength sheet steels for auto application. Journal of Metals. 1996; 7 : $26-30$

3. Durrenberger L., Lemoine X., Molinari A. Effects of pre-strain and bake-hardening on the crash properties of a top-hat section. Journal of Materials Processing Technology.2011; 211(12): 1937-1947.

4. Fischer F.D., Reisner G., Werner E., Tanaka K., Cailletaud G., Antretter T. A new view on transformation induced plasticity (TRIP). International Journal of Plasticity. 2000; 16(7-8): 723-748.

5. Wang W., Li M., He. Ch., Wei X., Wang D., Du $\mathrm{H}$. Experimental study on high strain rate behavior of high strength 600-1000 MPa dual phase steels and $1200 \mathrm{MPa}$ fully martensitic steels. Materials \& Design. 2013; 47: 510-521. 
6. Kuziak R., Kawalla R., Waengler S. Advanced high strength steels for automotive industry. Archives of Civil and Mechanical Engineering. 2008; 8(2): 103-117.

7. Mucha J., Kaščák L., Spišák E. Joining the car-body sheets using clinching process with various thickness and mechanical property arrangements. Archives of Civil and Mechanical Engineering. 2011; 11(1): 135-148.

8. Sarwar M., Priestner R. Influence of ferrite-martensite microstructural morphology on tensile properties of dual-phase steel. Journal of materials science. 1996; 31: 2091-2095.

9. Dewi H.S., Fischer A., Volpp J., Niendorf T., Kaplan A.F.H. Microstructure and mechanical properties of laser surface treated 44MnSiVS6 microalloyed steel. Optics and Laser Technology journal. 2020; 127: 106139.

10. Singh A.P., Pant G. Mechanical behaviour of vanadium microalloyed steel under control environment compression. Materials Today: Proceedings. 2020; 26(2): 2525-2527.

11. Gorni A.A., Mei P.R. Austenite transformation and age hardening of HSLA-80 and ULCB steels. Journal of Materials Processing Technology. 2004; 155-156: 1513-1518.

12. Show B.K., Veerababu R., Balamuralikrishnan R., Malakondaiah G. Effect of vanadium and titanium modification on the microstructure and mechanical properties of a microalloyed HSLA steel. Materials Science and Engineering. 2010; 527: 1595-1604.

13. Spišák E., Kaščák L., Viňáš J. Research into properties of joints of combined materials made by resistance spot welding. Chemické listy.2011; 105(16): 488-490.

14. Xing B., Xiao Y., Qin Q.H. Characteristics of shunting effect in resistance spot welding in mild steel based on electrode displacement. Measurement. 2018; 115: 233-242.

15. Deng L., Li Y.B., Carlson B.E., Sigler D.R. Effects of electrode surface topography on aluminum resistance spot welding. Welding Journal. 2018; 97(4): 120-132.

16. Xia Y., Su Z., Li Y., Zhou L., Shen Y. Online quantitative evaluation of expulsion in resistance spot welding. Journal of Manufacturing Processes.
2019; 46: 34-43.

17. Huang M., Zhang Q., Qi L., Deng L., Li Y. Effect of external magnetic field on resistance spot welding of aluminium alloy AA6061-T6. Journal of Manufacturing Processes. 2020; 50: 456-466.

18. Lambiase F., Di Ilio A. Finite element analysis of material flow in mechanical clinching with extensible dies. Journal of Materials Engineering and Performance. 2013; 22(6): 1629-1636.

19. Chen C., Zhang H., Peng H., Ran X., Pan Q. Investigation of the restored joint for aluminum alloy. Metals. 2020; 10(1): 97.

20. Lambiase F. Influence of process parameters in mechanical clinching with extensible dies. The International Journal of Advanced Manufacturing Technology. 2013; 66: 2123-2131.

21. Chen C., Ran X., Pan Q., Zhang H., Yi R., Han X. Research on the mechanical properties of repaired clinched joints with different forces. Thin-Walled Structures. 2020; 152: 106752.

22. Shi C., Yi R., Chen C., Peng H., Ran X., Zhao S. Forming mechanism of the repairing process on clinched joint. Journal of Manufacturing Processes. 2020;50:329-335.

23. He J., Lian J., Aretz A., Vajragupta N., Hangen U., Goodwin F., Münstermann S. Fracture properties of zinc coating layers in a galvannealed steel and an electrolytically galvanized steel. Materials Science \& Engineering: A. 2018; 732: 320-325.

24. Atia M.K.S., Jain M.K. Die-less clinching process and joint strength of AA7075 aluminum joints. Thin-Walled Structures. 2017; 120: 421-431.

25. Kaščák L., Spišák E., Kubík R., Mucha J. Finite element calculation of clinching with rigid die of three steel sheets. Strength of Materials. 2017; 49 (4): 488-499.

26. Viňáš J., Kaščák L'., Greš M. Optimization of resistance spot welding parameters for microalloyed steel sheets. Open Engineering. 2016;6(1):504-510.

27. Kaščák L', Mucha J., Witkowski W. Plastic Formed and Spot Welded Joints Strength of S350GD + Z Steel. Tehnički vjesnik. 2018; 25(6): 1623-1630.

28. Zhang H., Senkara J. Resistance welding: Fundamentals and Applications. Taylor and Francis; 2006. 